\title{
Nasal high-flow bronchodilator nebulization: a randomized cross-over study
}

\author{
François Reminiac ${ }^{1,2,3}$, Laurent Vecellio², Laetitia Bodet-Contentin ${ }^{1,4,5}$, Valérie Gissot ${ }^{4}$, Deborah Le Pennec ${ }^{2}$, \\ Charlotte Salmon Gandonnière ${ }^{1,4,5}$, Maria Cabrera², Pierre-François Dequin 1,2,4, Laurent Plantier ${ }^{2,6}$ \\ and Stephan Ehrmann ${ }^{1,2,4,5^{*}}$ (1)
}

\begin{abstract}
Background: There is an absence of controlled clinical data showing bronchodilation effectiveness after nebulization via nasal high-flow therapy circuits.

Results: Twenty-five patients with reversible airflow obstruction received, in a randomized order: (1) $2.5 \mathrm{mg}$ albuterol delivered via a jet nebulizer with a facial mask; (2) $2.5 \mathrm{mg}$ albuterol delivered via a vibrating mesh nebulizer placed downstream of a nasal high-flow humidification chamber $\left(30 \mathrm{~L} / \mathrm{min}\right.$ and $\left.37^{\circ} \mathrm{C}\right)$; and (3) nasal high-flow therapy without nebulization. All three conditions induced significant individual increases in forced expiratory volume in one second $\left(\mathrm{FEV}_{1}\right)$ compared to baseline. The median change was similar after facial mask nebulization [+ $350 \mathrm{~mL}$ $(+180 ;+550) ;+18 \%(+8 ;+30)]$ and nasal high flow with nebulization $[+330 \mathrm{~mL}(+140 ;+390) ;+16 \%(+5 ;+24)]$, $p=0.11$. However, it was significantly lower after nasal high-flow therapy without nebulization $[+50 \mathrm{~mL}(-10 ;+220)$; $+3 \%(-1 ;+8)], p=0.0009$. FEV 1 increases after facial mask and nasal high-flow nebulization as well as residual volume decreases were well correlated $(p<0.0001$ and $p=0.01)$. Both techniques showed good agreement in terms of airflow obstruction reversibility (kappa 0.60).
\end{abstract}

Conclusion: Albuterol vibrating mesh nebulization within a nasal high-flow circuit induces similar bronchodilation to standard facial mask jet nebulization. Beyond pharmacological bronchodilation, nasal high flow by itself may induce small but significant bronchodilation.

Keywords: Albuterol, Respiratory function tests, Nebulizers and vaporizers, Chronic obstructive pulmonary disease

\section{Background}

Nasal high-flow (NHF) therapy consists of delivering heated and humidified gas through a nasal cannula, at high flow rates, frequently exceeding patients' inspiratory flow. This non-invasive respiratory support is increasingly used, particularly among hypoxemic critically ill patients as those high oxygen flow rates very efficiently improve oxygenation and reduce the rate of intubation $[1,2]$. Nebulization is a technique used to deliver inhaled drugs directly acting on the respiratory tract. In critically ill patients, nebulization is very frequently used, in

\footnotetext{
*Correspondence: stephanehrmann@gmail.com

${ }^{1}$ Médecine Intensive Réanimation, CHRU de Tours, 2, Bd Tonnellé, 37044 Tours Cedex 9, France

Full list of author information is available at the end of the article
}

particular among patients undergoing non-invasive respiratory support [3]. The most frequently delivered inhaled drugs are bronchodilators, such as albuterol, provided to approximately $20 \%$ of patients in intensive care [3]. Thus, one may question the best way to combine the two therapies in order to deliver inhaled bronchodilators to patients undergoing NHF therapy. Indeed, NHF may be especially beneficial to patients suffering obstructive pulmonary disease for whom inhaled bronchodilator delivery is a cornerstone of therapy [4-6]. NHF washes out the anatomical dead space clearing exhaled carbon dioxide, and this may have benefit to patients with hypercapnia $[7,8]$; it induces a positive end-expiratory pressure, a reduction in respiratory rate and increase in tidal volume, which all potentially lead to a reduction in the work of breathing among patients with dynamic 
hyperinflation $[9,10]$; it enables precise control of the inspired fraction of oxygen to avoid excessive delivery among patients with chronic hypercapnia and altered respiratory drive; it ensures high humidification of inhaled gases favouring mucus hydration and thus clearance and is a very well-tolerated oxygen delivery method. Nevertheless, NHF merely represents an obstacle impeding inhaled drug delivery. Indeed, high gas flow rate and associated turbulent flow, high gas humidity, geometric angulation of the nasal cannula, and the nose anatomy physiologically retaining inhaled particles all represent hurdles to efficient inhaled drug delivery through an NHF circuit. In vitro data showed that when placing a vibrating mesh nebulizer close to the humidification chamber and limiting the system flow rate at $30 \mathrm{~L} / \mathrm{min}$, significant amounts of drug may be delivered to the respiratory tract [11-15]. That data have been confirmed by in vivo evaluation in a paediatric animal model and in adult radiolabelled deposition studies [16, 17]. Although uncontrolled case series are in favour of a clinically significant bronchodilation after delivery of albuterol through an NHF circuit, no controlled data are available in humans [18].

The objective of this study was to investigate the effect of vibrating mesh nebulized albuterol delivered through an NHF circuit on respiratory system mechanics as compared to Standard-nebulization using a jet nebulizer with a facial mask and NHF delivered without inhaled albuterol in a randomized controlled fashion.

\section{Methods}

The study was approved by the institutional review board (Comité de Protection des Personnes Ouest1, 2016-R6-PHAO15-SE/Airvoneb-2016-A00064-47, NCT02812979). Adult patients with reversible obstructive lung disease defined as a baseline of forced expiratory volume in one second $\left(\mathrm{FEV}_{1}\right)$ over vital capacity ratio below $70 \%$ and a positive bronchodilator reversibility test $\left(\mathrm{FEV}_{1}\right.$ increase of at least $12 \%$ and $200 \mathrm{~mL}$ after inhaled albuterol delivery [19]) as assessed in the past month were included after written informed consent. Non-inclusion criteria were ongoing exacerbation, hemoptysis, uncontrolled asthma, recent pneumothorax, lung or pleural biopsy, broncho-alveolar lavage, pregnancy, breast feeding, trusteeship, guardianship and albuterol allergy or intolerance. Patients underwent, on three separate days within 1 week, in a randomized order: (1) albuterol nebulization through a facial aerosol mask (Standard-nebulization), (2) albuterol nebulization within an NHF circuit (NHF-nebulization) and (3) sham nebulization within an NHF circuit (Control-NHF). Patients were instructed not to smoke or to take shortor long-acting bronchodilators, respectively 4,6 and $12 \mathrm{~h}$ prior to each procedure.

\section{Standard-nebulization}

$2.5 \mathrm{mg}$ albuterol (albuterol sulphate $2.5 \mathrm{mg} / 2.5 \mathrm{~mL}$, Mylan N.V., Canonsburg, PA, USA) was placed in a jet nebulizer connected to a bucco-nasal facial mask positioned on the patient and driven with $6 \mathrm{~L} / \mathrm{min}$ of nonheated and non-humidified pressurized air (Cirrus2 nebulizer and Adult EcoLite ${ }^{\mathrm{TM}}$ Aerosol Mask, both from Intersurgical, Wokingham, UK).

\section{NHF-nebulization}

$2.5 \mathrm{mg}$ albuterol was placed in a vibrating mesh nebulizer (Aerogen Solo ${ }^{\circledR}$, Aerogen Ltd., Galway, Ireland) positioned immediately downstream of the humidification chamber of an NHF system (Airvo ${ }^{\mathrm{TM}} 2$, Fisher \& Paykel Healthcare, Auckland, New Zealand), using the Airvo ${ }^{\mathrm{TM}} \mathrm{Neb}$ connector (Fig. 1). NHF was set at $30 \mathrm{~L} / \mathrm{min}$ of air with $100 \%$ relative humidity at $37^{\circ} \mathrm{C}$ using medium size nasal cannula. The NHF session lasted $30 \mathrm{~min}$, and nebulization was started after 10 min of NHF therapy.

\section{Control-NHF}

The patient was placed under NHF during $30 \mathrm{~min}$ in the same conditions as for NHF-nebulization with an empty nebulizer. The patient was kept blind between the NHFnebulization and Control-NHF procedures.

The primary outcome was the relative increase in FEV $_{1}$ after NHF-nebulization as compared to Standardnebulization. Pulmonary function tests (spirometry and plethysmography; calibrated Jaeger MasterScreen body plethysmograph, Spirometry SentrySuite v2.10, CareFusion, Rolle, Switzerland) were performed before and after each procedure, according to guidelines [19]. Spirometry was started immediately after the end of the $30 \mathrm{~min}$ NHF sessions, at least $10 \mathrm{~min}$ after the end of nebulization. Pulmonary function tests were performed following

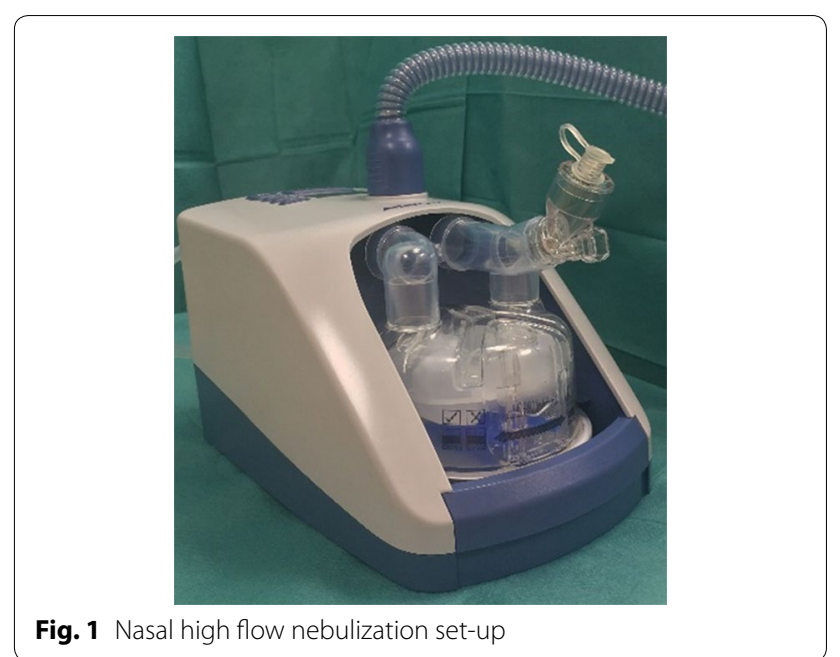


the same time span after the end of NHF therapy in both conditions comprising NHF (NHF-nebulization and Control-NHF) and following the same time span after the end of nebulization in both conditions comprising active nebulization (Standard-nebulization and NHF-nebulization).

Plethysmography loops were evaluated, and patients were classified as presenting expiratory flow limitation or not $[20,21]$. Volumetric capnography was performed before and after each procedure (5 duplicate measurements, patients breathing out at slow and steady flow from maximal inspiration to maximal expiration) and the slope of the third phase of the capnogram measured. All pulmonary function tests were performed and interpreted by investigators and technicians blind to the procedure randomization. Patients' comfort was recorded using a visual analogical scale (range $0-100$, with higher scores indicating higher comfort). The NHF-nebulization set-up and vibrating mesh nebulizer performance were tested in vitro prior to the clinical study (see Additional file 1).

\section{Statistical analysis}

The sample size calculation was based on previous data which showed a standard deviation of $\mathrm{FEV}_{1}$ of $10 \%$ of the baseline value [22]. Taking into account the cross-over design, this non-inferiority trial, testing the hypothesis that NHF-nebulization is non-inferior to Control-nebulization in terms of $\mathrm{FEV}_{1}$ relative increase, with a non-inferiority margin of $8 \%$, a unilateral alpha risk of $2.5 \%$ and a beta risk of $10 \%$, had to enrol 24 patients.

An association between the randomization order and primary outcome was assessed looking for interaction between the relative increase in $\mathrm{FEV}_{1}$ and the procedure position to rule out a carry-over or learning effect on pulmonary function tests (nonparametric Kruskal-Wallis test). To partition the increase in $\mathrm{FEV}_{1}$ potentially due to NHF alone from the pharmacological effect of albuterol nebulization, the $\mathrm{FEV}_{1}$ increase attributable to albuterol nebulization was calculated individually, by subtracting Control-NHF-induced absolute $\mathrm{FEV}_{1}$ increase from NHF-nebulization-induced absolute $\mathrm{FEV}_{1}$ increase.

Quantitative variables were expressed as median and interquartile range and were compared before and after each procedure using a Wilcoxon signed rank test. Individual changes (before/after the procedure) were compared between procedures (Standard-nebulization, NHF-nebulization and Control-NHF) using the nonparametric Friedman test accounting for the cross-over design, and if significant, two-by-two comparisons were performed with the Wilcoxon signed rank test. Correlation between quantitative variables was evaluated with the Spearman correlation coefficient. Qualitative variables were expressed as counts and percentages. The agreement between Standard-nebulization and NHFnebulization in terms of airway obstruction reversibility (200 mL absolute and $12 \%$ relative increase in $\mathrm{FEV}_{1}$ [19]) was assessed using the kappa coefficient. A $p$ value $<0.05$ was considered significant.

\section{Results}

In vitro results are presented in the Additional file 1. From June 2016 to April 2018, 11,288 patients underwent pulmonary function tests, 4905 spirometry with plethysmography, and beta-2-adrenergic agonist-induced reversibility was tested in 3552 patients of which 25 were included (Table 1).

\section{FEV change}

After Standard-nebulization, $\mathrm{FEV}_{1}$ significantly increased from $1.77 \mathrm{~L}(1.43 ; 2.16)$ to $2.20 \mathrm{~L}(1.69 ; 2.47), p<0.0001$ (Table 2). Individual absolute and relative increases in $\mathrm{FEV}_{1}$ were, respectively, $350 \mathrm{~mL}(180 ; 550)$ and $18 \%(8$; 30). NHF-nebulization similarly induced a significant $\mathrm{FEV}_{1}$ increase: $1.77 \mathrm{~L}(1.47 ; 2.27)$ to $2.14 \mathrm{~L}(1.71 ; 2.41)$, $p<0.0001$, with individual absolute and relative increases of $330 \mathrm{~mL}(140 ; 390)$ and $16 \%(5 ; 24)$ : Fig. 2.

After Control-NHF without bronchodilator delivery, $\mathrm{FEV}_{1}$ increased from $1.83 \mathrm{~L}(1.36 ; 2.42)$ to $1.93 \mathrm{~L}$ (1.27; 2.52), $p=0.044$ : Fig. 2. Median individual absolute and

\section{Table 1 Patients' baseline characteristics}

\begin{tabular}{lc}
\hline Variable & $\boldsymbol{N}=\mathbf{2 5}$ \\
\hline Female/male & $10(40 \%) / 15(60 \%)$ \\
Age (years) & $60(53 ; 68)$ \\
Main respiratory disease & \\
Asthma & $9(36 \%)$ \\
COPD & $14(56 \%)$ \\
Other & $2(8 \%)$ \\
Height (cm) & $169(165 ; 176)$ \\
Weight (kg) & $75(64 ; 80)$ \\
Body mass index (high/weight $\left.{ }^{2}\right)$ & $26(23 ; 29)$ \\
FEV ${ }_{1}(L)$ & $1.83(1,38 ; 2,03)$ \\
Percentage of predicted $(\%)$ & $60(53 ; 71)$ \\
FEV ${ }_{1} /$ vital capacity $(\%)$ & $54(45 ; 60)$ \\
Functional residual capacity $(\mathrm{L})$ & $5,0(3,9 ; 6,0)$ \\
Percentage of predicted $(\%)$ & $150(139 ; 171)$ \\
Residual volume (L) & $4,0(2,9 ; 4,4)$ \\
Percentage of predicted $(\%)$ & $172(154 ; 184)$ \\
Presence of expiratory flow limitation & $6(24 \%)$ \\
\hline Data are presented as count (percentage) & \\
\hline
\end{tabular}

Data are presented as count (percentage) and median (interquartile range) COPD chronic obstructive pulmonary disease, $F E V_{1}$ forced expiratory volume in one second 
Table 2 Spirometry, plethysmography and volumetric capnography results

\begin{tabular}{|c|c|c|c|c|c|c|c|c|c|}
\hline & \multicolumn{3}{|c|}{ Standard-nebulisation } & \multicolumn{3}{|c|}{ NHF-nebulization } & \multicolumn{3}{|c|}{ Control-NHF } \\
\hline & Before & After & $\begin{array}{l}\text { Individual } \\
\text { change }\end{array}$ & Before & After & $\begin{array}{l}\text { Individual } \\
\text { change }\end{array}$ & Before & After & $\begin{array}{l}\text { Individual } \\
\text { change }\end{array}$ \\
\hline $\mathrm{FEV}_{1}(\mathrm{~L})$ & $\begin{array}{l}1.77 \\
(1.43 ; 2.16)\end{array}$ & $\begin{array}{l}2.20 \\
(1.69 ; 2.47)\end{array}$ & $\begin{array}{c}0.350(0.180 \\
0.550)^{*} \\
18 \%(8 ; 30)^{*}\end{array}$ & $\begin{array}{l}1.77 \\
(1.47 ; 2.27)\end{array}$ & $\begin{array}{l}2.14 \\
(1.71 ; 2.41)\end{array}$ & $\begin{array}{l}0.330(0.140 ; \\
0.390)^{*} \\
16 \%(5 ; 24)^{*}\end{array}$ & $\begin{array}{l}1.83 \\
(1.36 ; 2.42)\end{array}$ & $\begin{array}{l}1.93 \\
(1.27 ; 2.52)\end{array}$ & $\begin{array}{l}0.050(-0.010 ; \\
0.220)^{*} \\
3 \%(-1 ; 8)^{*}\end{array}$ \\
\hline $\begin{array}{l}\text { Functional } \\
\text { residual } \\
\text { capacity }(\mathrm{L})\end{array}$ & $\begin{array}{l}4.58 \\
(3.89 ; 5.22)\end{array}$ & $\begin{array}{l}4.07 \\
(3.42 ; 4.88)\end{array}$ & $\begin{array}{l}-0.33 \\
(-0.71 ;-0.17)^{*}\end{array}$ & $\begin{array}{l}4.42 \\
(3.67 ; 5.35)\end{array}$ & $\begin{array}{l}4.04 \\
(3.45 ; 5.09)\end{array}$ & $\begin{array}{l}-0.40 \\
(-0.64 ;-0.12)^{*}\end{array}$ & $\begin{array}{l}4.58 \\
(3.80 ; 5.38)\end{array}$ & $\begin{array}{l}4.42 \\
(3.72 ; 5.53)\end{array}$ & $\begin{array}{l}-0.02 \\
(-0.24 ; 0.10)\end{array}$ \\
\hline $\begin{array}{l}\text { Residual vol- } \\
\text { ume }(\mathrm{L})\end{array}$ & $\begin{array}{l}3.42 \\
(2.63 ; 4.22)\end{array}$ & $\begin{array}{l}2.89 \\
(2.42 ; 3.54)\end{array}$ & $\begin{array}{l}-0.37 \\
(-0.82 ;-0.12)^{*}\end{array}$ & $\begin{array}{l}3.22 \\
(2.53 ; 4.29)\end{array}$ & $\begin{array}{l}2.90 \\
(2.52 ; 4.20)\end{array}$ & $\begin{array}{l}-0.34 \\
(-0.64 ;-0.06)^{*}\end{array}$ & $\begin{array}{l}3.27 \\
(2.76 ; 3.99)\end{array}$ & $\begin{array}{l}3.19 \\
(2.72 ; 4.56)\end{array}$ & $\begin{array}{l}-0.09 \\
(-0.34 ; 0.16)\end{array}$ \\
\hline $\begin{array}{l}\text { Forced vital } \\
\text { capacity }(\mathrm{L})\end{array}$ & $\begin{array}{l}3.57 \\
(2.66 ; 4.39)\end{array}$ & $\begin{array}{l}3.65 \\
(3.15 ; 4.59)\end{array}$ & $\begin{array}{l}0.32 \\
(0.08 ; 0.57)^{*}\end{array}$ & $\begin{array}{l}3.41 \\
(2.79 ; 4.37)\end{array}$ & $\begin{array}{l}3.51 \\
(3.05 ; 4.47)\end{array}$ & $\begin{array}{l}0.11 \\
(0.00 ; 0.34)^{*}\end{array}$ & $\begin{array}{l}3.28 \\
(2.74 ; 4.52)\end{array}$ & $\begin{array}{l}3.58 \\
(2.64 ; 4.42)\end{array}$ & $\begin{array}{l}0.10 \\
(-0.10 ; 0.25)\end{array}$ \\
\hline $\begin{array}{l}\text { Plethysmo- } \\
\text { graphic } \\
\text { airway resist- } \\
\text { ances (raw) }\end{array}$ & $\begin{array}{l}5.31 \\
(3.72 ; 6.94)\end{array}$ & $\begin{array}{l}2.89 \\
(2.54 ; 3.80)\end{array}$ & $\begin{array}{l}-2.06 \\
(-3.82 ;-0.96)^{*}\end{array}$ & $\begin{array}{l}4.62 \\
(3.48 ; 7.27)\end{array}$ & $\begin{array}{l}3.10 \\
(2.39 ; 3.79)\end{array}$ & $\begin{array}{l}-1.89 \\
(-3.36 ;-0.69)^{*}\end{array}$ & $\begin{array}{l}4.71 \\
(3.22 ; 7.02)\end{array}$ & $\begin{array}{l}4.64 \\
(2.86 ; 5.77)\end{array}$ & $\begin{array}{l}-0.39 \\
(-1.02 ; 0.04)^{*}\end{array}$ \\
\hline $\begin{array}{l}\text { Inspiratory } \\
\text { capacity (L) }\end{array}$ & $\begin{array}{l}2.36 \\
(2.03 ; 2.71)\end{array}$ & $2.63(2.26 ; 3.34)$ & $\begin{array}{l}0.30 \\
(0.14 ; 0.54)^{*}\end{array}$ & $\begin{array}{l}2.59 \\
(2.12 ; 2.90)\end{array}$ & $\begin{array}{l}2.72 \\
(2.17 ; 3.17)\end{array}$ & $\begin{array}{l}0.20 \\
(0.05 ; 0.47)^{*}\end{array}$ & $\begin{array}{l}2.21 \\
(1.78 ; 2.97)\end{array}$ & $\begin{array}{l}2.61 \\
(1.93 ; 2.91)\end{array}$ & $\begin{array}{l}0.10 \\
(-0.07 ; 0.20)\end{array}$ \\
\hline $\begin{array}{l}\text { Part III of the } \\
\text { volumetric } \\
\text { capnography } \\
\text { slope }(n=16)\end{array}$ & $\begin{array}{l}0.56 \\
(0.47 ; 0.74)\end{array}$ & $\begin{array}{l}0.66 \\
(0.51 ; 0.92)\end{array}$ & $\begin{array}{l}0.04 \\
(-0.03 ; 0.13)\end{array}$ & $\begin{array}{l}0.67 \\
(0.41 ; 0.94)\end{array}$ & $\begin{array}{l}0.64 \\
(0.40 ; 0.98)\end{array}$ & $\begin{array}{l}0.03 \\
(-0.11 ; 0.08)\end{array}$ & $\begin{array}{l}0.62 \\
(0.47 ; 0.89)\end{array}$ & $\begin{array}{l}0.65 \\
(0.45 ; 0.91)\end{array}$ & $\begin{array}{l}0.01 \\
(-0.05 ; 0.12)\end{array}$ \\
\hline
\end{tabular}

Standard-nebulization consisted in $2.5 \mathrm{mg}$ albuterol delivery with a jet nebulizer connected to an aerosol facial mask; NHF-nebulization: 2.5 mg albuterol delivered within a nasal high-flow (NHF) circuit; Control-NHF: nasal high flow without nebulization

$F E V_{1}$ forced expiratory volume in one second, NHF nasal high-flow

${ }^{*} p<0.05$ for individual changes before and after each session with one technique

relative increases were $50 \mathrm{~mL}(-10 ; 220)$ and $3 \%(-1$; 8): Table 2.

No interaction was observed between the randomization order of the procedures and the absolute and relative increase in $\operatorname{FEV}_{1}(p=0.66$ and $p=0.59$, respectively). There was an overall statistically significant difference between procedures for the absolute and relative increase in $\operatorname{FEV}_{1}(p<0.001$ and $p=0.001$, respectively). In two-by-two comparisons, changes in $\mathrm{FEV}_{1}$ after NHF-nebulization and Standard-nebulization were not significantly different (Fig. 2) and well correlated (Fig. 3) and exhibited low bias (Figure E3 of the Additional file 1). Changes in $\mathrm{FEV}_{1}$ after Control-NHF were significantly lower (Fig. 2). Of note, when calculating changes attributable to albuterol nebulization during NHF-nebulization (subtracting Control-NHF-induced changes from NHF-nebulization-induced changes), the individual absolute increase in $\mathrm{FEV}_{1}$ attributable to albuterol nebulization was $230 \mathrm{~mL}(-45 ; 385)$, a value significantly lower than the $\mathrm{FEV}_{1}$ increase after Standard-nebulization $(p=0.009)$.

\section{Airflow obstruction reversibility}

Of the 18 patients with an increase in $\mathrm{FEV}_{1}$ of more than $200 \mathrm{~mL}$ after Standard-nebulization during study measurements, 14/18 (78\%) also showed such an increase after NHF-nebulization. Seventeen patients had an increase in $\mathrm{FEV}_{1}$ of more than $12 \%$ after Standard-nebulization, of these 15/17 (88\%) did so after NHF-nebulization. Combining both criteria according to guidelines (absolute and relative increase in $\mathrm{FEV}_{1}$ [19]), 16 patients met the criteria for airway obstruction reversibility after albuterol Standard-nebulization during study measurements, all but two of these $(n=14 / 16,88 \%)$ met the criteria after albuterol NHF-nebulization; conversely, all but one of the patients meeting the criteria after NHF-nebulization (13/14 93\%) did so after Standard-nebulization (kappa $0.60,95 \%$ confidence interval 0.29-0.90).

Of note, after Control-NHF, 8/25 patients (32\%) had an $\mathrm{FEV}_{1}$ increase of at least $200 \mathrm{~mL}$ and $5 / 25(20 \%)$ of at least $12 \%$. Five patients $(20 \%)$ met the criteria for airway obstruction reversibility after Control-NHF without the addition of a bronchodilator drug [19]. See Additional file 1: Table E2 for details on those patients. No association was observed between expiratory flow limitation observed on plethysmographic loop inspection (observed in 6 patients) and positive response in terms of $\mathrm{FEV}_{1}$ 


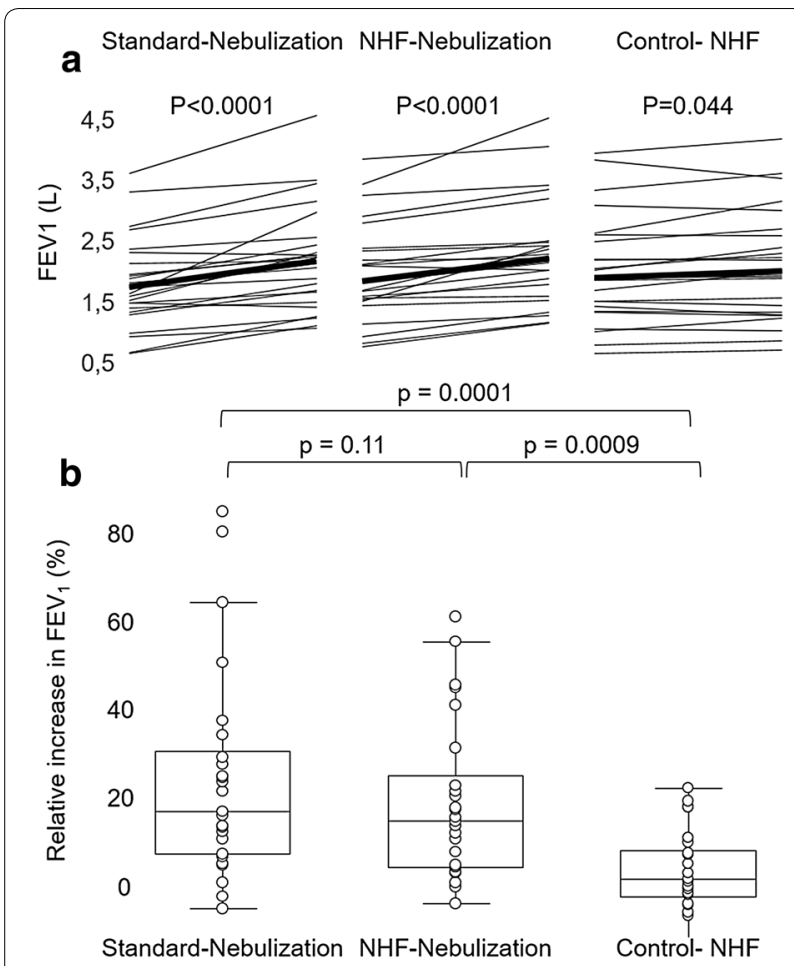

Fig. 2 Individual change in forced expiratory volume in one second. a Individual values of forced expiratory volume in one second are indicate before and after each procedure at the left and right of each panel, respectively. The thick line represents the median values of the population. $\mathbf{b}$ Relative changes in forced expiratory volume in one second were similar and not significantly different between Standard-nebulization and nasal high-flow nebulization, whereas changes were significantly lower when implementing nasal high-flow without nebulization. Standard-nebulization consisted in $2.5 \mathrm{mg}$ albuterol delivery with a jet nebulizer connected to an aerosol facial mask, nasal high-flow nebulization consisted in $2.5 \mathrm{mg}$ albuterol delivered within a nasal high-flow circuit, and Control-nasal high-flow consisted in nasal high-flow delivered without nebulization. NHF nasal high-flow, FEV forced expiratory volume in one second

increases after Control-NHF, as only one flow limited patient showed such a positive response.

\section{Other pulmonary function tests}

Plethysmography showed significant improvement in lung volumes after Standard-nebulization and NHFnebulization (Table 2). Significant individual reduction in functional residual capacity was observed after NHF-nebulization: from $4.42 \mathrm{~L}(3.67 ; 5.35)$ to $4.04 \mathrm{~L}$ (3.45; 5.09)-individual changes $-400 \mathrm{~mL}$ (-640; $-120), p=0.001$. This change was correlated with changes in residual volume observed after Standardnebulization: Fig. 3. When NHF was delivered without albuterol nebulization, no such significant volume changes occurred (Table 2). Significant changes in

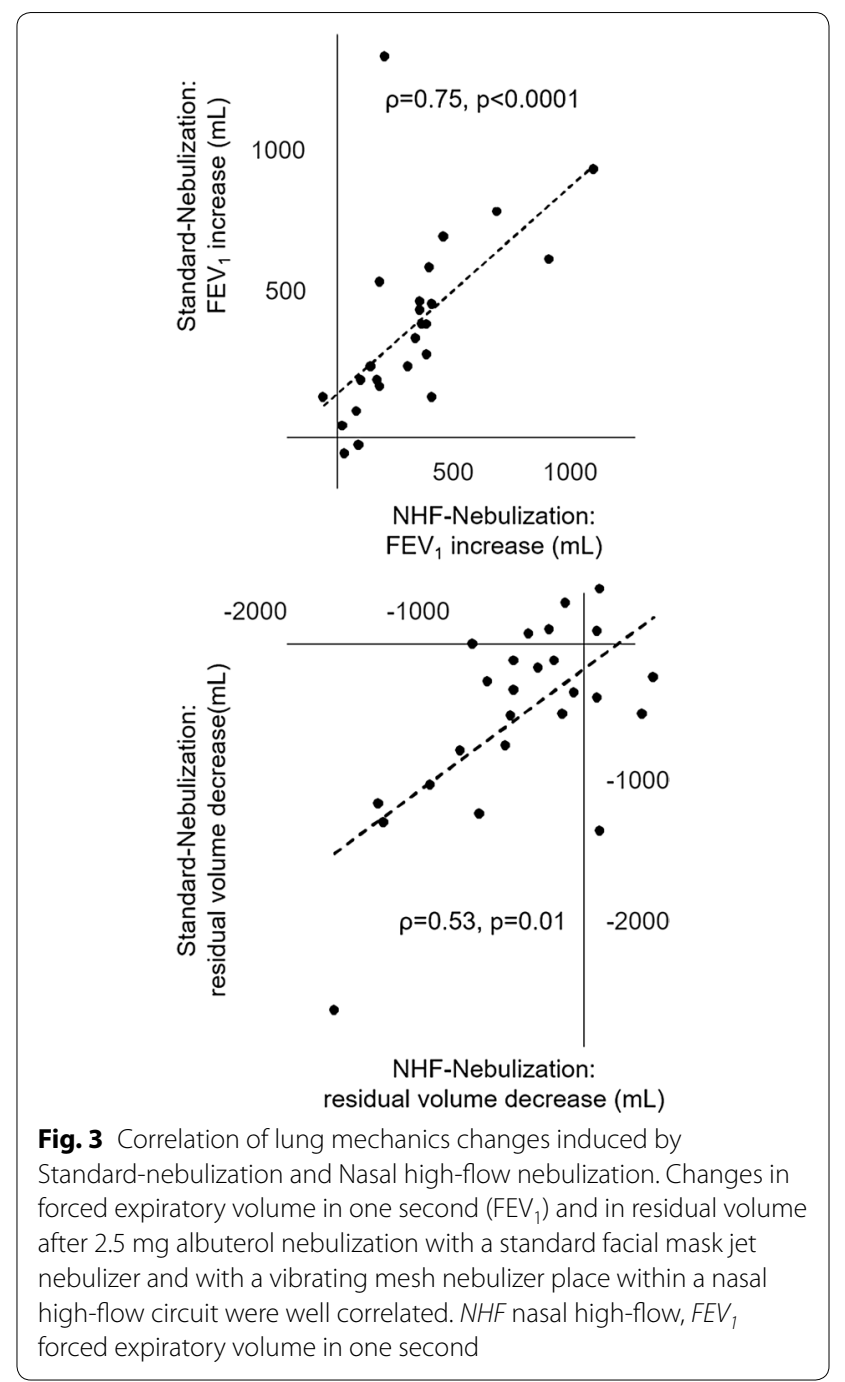

plethysmography-measured airway resistances also occurred after Standard-nebulization, NHF-nebulization and Control-NHF (Table 2). The third part of the expired volumetric capnogram, which could be measured for all procedures in sixteen patients, did not show a significant change after either procedure, and individual changes were not significantly different between procedures $(p>0.05)$.

\section{Tolerance}

Overall tolerance of the NHF therapy and nebulization was excellent. No side effects were recorded during NHFnebulization; one patient complained of moderate reversible dyspnoea during Standard-nebulization and during Control-NHF. No clinically significant changes in heart rate and respiratory rate occurred; individual changes were not statistically different between procedures (data 
not shown). Comfort, as measured by the visual analogical scale, was not significantly different between procedures, 85 (77; 96), $85(65 ; 93)$ and $82(66$; 92) for Standard-nebulization, NHF-nebulization and ControlNHF, respectively $(p=0.34)$.

\section{Discussion}

In patients with reversible obstructive pulmonary disease, away from an exacerbation, albuterol delivered by vibrating mesh nebulization through an NHF circuit appeared non-inferior to standard facial mask jet nebulization in terms of $\mathrm{FEV}_{1}$ increase. This was in part due to a small but a significant increase in $\mathrm{FEV}_{1}$ due to NHF without the addition of bronchodilator nebulization. To the best of our knowledge, this is the first controlled study in adults documenting clinical efficacy of nebulization within an NHF circuit adequately controlling for all confounding factors. These results have important clinical implications. As the use of NHF is expanding, physicians will increasingly be faced with patients undergoing NHF and requiring inhaled bronchodilator therapy [23]. Given the lack of controlled data, interrupting NHF therapy to deliver the inhaled medication may currently be the preferred option; these results show that albuterol can be delivered within the NHF circuit with the same efficacy and tolerance avoiding cumbersome equipment switches. These results are in line with the study of Bräunlich et al. who used a homecare NHF device to deliver a combination of albuterol and ipratropium bromide placing a jet nebulizer close to the nasal cannula but lacked a control group without nebulization [24]. Of note, positioning the nebulizer close to the nasal cannula may be suboptimal, as it favours aerosol deposition in the cannula. This deposition reduces drug delivery to the patient but was also associated with aerosol nasal dripping which may impact patients' comfort [11]. Our results provide controlled evidence supporting the observation made by Morgan et al. of efficient albuterol delivery after nebulization within a NHF circuit set-up similar to the present one among children with acute bronchiolitis [18].

Effects of NHF without bronchodilator nebulization on pulmonary function tests are of complex interpretation. We observed a statistically significant increase in $\mathrm{FEV}_{1}$ after Control-NHF, albeit modest in magnitude (median increase of $50 \mathrm{~mL}$ and 3\%, values below validated thresholds to define reversibility [19]); this result supports the hypothesis of an NHF-induced bronchodilation. Interestingly, $20 \%$ of the patients showed significant increases in $\mathrm{FEV}_{1}$ after Control-NHF meeting guideline criteria for airflow obstruction reversibility without having received a bronchodilator. Of note, $\mathrm{FEV}_{1}$ was measured after interruption of NHF in patients breathing spontaneously unlike other physiological studies which observed an increase in lung volumes measured during NHF therapy [25]. This may also explain the lack of association between flow limitation and $\mathrm{FEV}_{1}$ increase after Control-NHF. Plethysmography-measured lung volumes were not significantly affected by NHF in the present study. One can speculate on potential mechanism such as positive airway pressure and improved mucus hydration during the 30-min NHF session leading to the significant increase in $\mathrm{FEV}_{1}$ once the therapy is interrupted. Indeed, improved mucus clearance may lead to improved lung mechanics; however, no major cough and expectoration was observed among the included patients. NHF may also induce changes in respiratory pattern potentially leading to higher tidal volume and eventually to deeper inspiration during spirometry manoeuvres. Such mechanisms will need to be investigated in the future, particularly given the ongoing studies evaluating NHF among patients suffering obstructive pulmonary disease. This study has important limitations. Only stable patients were included; thus, extrapolation to the acute care setting of unstable decompensated patients warrants evaluation. Results cannot be extrapolated to other pharmacological classes, as the favourable results observe here in terms of nebulization efficiency during NHF are due in part to the large therapeutic index of albuterol [26]. Deposition studies performed in humans suggest other drugs like antibiotics are unlike effective when inhaled through an NHF circuit [17]. Clinical efficacy studies are required in intensive care unit, emergency department and pulmonology ward patients. Two different nebulizers were used in the study. We aimed to compare usual practice (facial mask jet nebulization) to the new modality of NHF-nebulization using a vibrating mesh nebulizer. Jet nebulization within the NHF circuit, albeit feasible, comes with important limitations as the gas driving the nebulizer interferes with the NHF oxygen content, humidity and temperature. Vibrating mesh facial mask nebulization is currently of uncommon practice. Thus, the potential limit of using different nebulizers represents a pragmatic choice favouring clinical applicability of the results. Using jet nebulization in combination with nasal high-flow therapy would need further evaluation. Of note, the study did not comprise a condition of sham jet nebulization to delineate individual effect of beta-2-adrenergic agonist nebulization per se. Only one NHF setting (temperature, flow rate, cannula size) and one dose of albuterol were evaluated clinically. However, results in other conditions, tested in the bench study, can give indications of potential dose adjustments, in case of nebulization with higher flow rates for example. The significantly improved delivery observed in vitro with 
non-humidified settings allows for new innovation in NHF devices to improve combined inhaled drug delivery.

In conclusion, the present work shows that albuterol vibrating mesh nebulization within an NHF circuit induces similar $\mathrm{FEV}_{1}$ increases and patient comfort and tolerance compared to standard facial mask jet nebulization and can be implemented in clinical practice. Beyond pharmacologically induced bronchodilation, NHF by itself may induce a small but significant increase in $\mathrm{FEV}_{1}$ which deserves further evaluation.

\section{Additional file}

Additional file 1. In vitro testing and additional clinical results.

\section{Abbreviations}

NHF: nasal high-flow; FEV : forced expiratory volume in one second; Standardnebulization: albuterol nebulization through a facial aerosol mask; NHF-nebulization: albuterol nebulization within a nasal high-flow circuit; Control-NHF: sham nebulization within a nasal high-flow circuit.

\section{Authors' contributions}

$F R, L V, V G, L P$ and $S E$ were involved in study design and conception. FR, LV, $\angle B C, D L P, C S G, M C, P F D, L P$ and SE contributed to in vitro and clinical data acquisition. FR, LV, LP and SE analysed and interpreted the data. SE drafted the manuscript. FR, LV, LBC, VG, DLP, CSG, MC, PFD, LP and SE reviewed the manuscript for important intellectual content. All authors read and approved the final manuscript.

\section{Author details}

${ }^{1}$ Médecine Intensive Réanimation, CHRU de Tours, 2, Bd Tonnellé, 37044 Tours Cedex 9 , France. ${ }^{2}$ Centre d'étude des pathologies respiratoires, INSERM U1 100, Faculté de médecine, Université de Tours, Tours, France. ${ }^{3}$ Clinique du Mail, La Rochelle, France. ${ }^{4}$ Centre d'investigation clinique, INSERM CIC 1415, CHRU de Tours, Tours, France. ${ }^{5}$ CRICS-TRIGGERSEP Network, Tours, France. ${ }^{6}$ Service de pneumologie et d'explorations fonctionnelles respiratoires, CHRU de Tours, Tours, France.

\section{Acknowledgements}

The authors sincerely thank Helene BANSARD and Lysiane BRICK from the Centre d'Investigation Clinique, INSERM CIC 1415, CHRU de Tours, Tours, France, for their invaluable help to carry out the study, gathering data and organizing study logistics, Sylvie ANGELLIAUME, Agnes BAUGE, Nathalie ROUILLARD and Nathalie JEAN from the Service de pneumologie et d'explorations fonctionnelles respiratoires, CHRU de Tours, Tours, France, for performing patients screening and carrying out pulmonary function tests, Annouck BAROUGIER and Lucas FISCHER from Service de Médecine Intensive Réanimation, and Marie LECLERC from Délégation à la Recherche Clinique et à I'Innovation, CHRU de Tours, Tours, France, for data management.

\section{Competing interests}

SE declares consultancies fees from Aerogen, Baxter healthcare and La Diffusion Technique Française, research support from Aerogen, Fisher \& Paykel and Hamilton, travel expenses reimbursement from Aerogen and Fisher \& Paykel. Others authors declare that they have no competing interests. LV is an employee of Nemera.

\section{Availability of data and materials}

The data sets used and/or analysed during the current study are available from the corresponding author on reasonable request.
Consent for publication

Not applicable.

\section{Ethics approval and consent to participate}

The study was approved by the institutional review board (Comite de Protection des Personnes Ouest-1, 2016-R6-PHAO15-SE/Airvoneb-2016-A00064-47, NCT02812979). All patients were included after written informed consent.

\section{Funding}

The study was funded by an unrestricted grant from Fisher \& Paykel Healthcare Limited, Auckland, New Zealand. Nebulizers were provided free of charge by Aerogen Limited, Galway, Ireland.

\section{Publisher's Note}

Springer Nature remains neutral with regard to jurisdictional claims in published maps and institutional affiliations.

Received: 15 October 2018 Accepted: 11 December 2018

Published online: 20 December 2018

\section{References}

1. Frat JP, Thille AX, Mercat A, Girault C, Ragot S, Perbet S, et al. High-flow oxygen through nasal cannula in acute hypoxemic respiratory failure. $\mathrm{N}$ Engl J Med. 2015;372:2185-96.

2. Zhu Y, Yin H, Zhang R, Wei J. High-flow nasal cannula oxygen therapy versus conventional oxygen therapy in patients with acute respiratory failure: a systematic review and metaanalysis of randomized controlled trials. BMC Pulm Med. 2017;17:201.

3. Ehrmann S, Roche-Campo F, Bodet-Contentin L, Razazi K, Dugernier J, Trenado-Alvarez J, et al. Aerosol therapy in intensive and intermediate care units: prospective observation of 2808 critically ill patients. Intensive Care Med. 2016;42:192-201.

4. Pisani L, Vega ML. Use of nasal high flow in stable COPD: rational and physiology. COPD. 2017;14:346-50.

5. Spoletini G, Alotaibi M, Blasi F, Hill NS. Heated humidified high-flow nasal oxygen in adults: mechanisms of action and clinical implications. Chest. 2015;148:253-61.

6. Pisani L, Fasano L, Corcione N, Comellini V, Musti MA, Brandao M, et al. Change in pulmonary mechanics and the effect on breathing pattern of high flow oxygen therapy in stable hypercapnic COPD. Thorax. 2017;72:373-5.

7. Onodera Y, Akimoto R, Suzuki H, Okada M, Nakane M, Kawamae K. A highflow nasal cannula system with relatively low flow effectively washes out $\mathrm{CO}_{2}$ from the anatomical dead space in a sophisticated respiratory model made by a 3D printer. Intensive Care Med Exp. 2018;6:7.

8. Möller W, Feng S, Domanski U, Franke KJ, Celik G, Bartenstein P, et al. Nasal high flow reduces dead space. J Appl Physiol. 2017;122:191-7.

9. Vargas F, Saint-Leger M, Boyer A, Bui NH, Hilbert G. Physiologic effects of high-flow nasal cannula oxygen in critical care subjects. Respir Care. 2015;60:1369-76.

10. Fraser JF, Spooner AJ, Dunster KR, Anstey CM, Corley A. Nasal high flow oxygen therapy in patients with COPD reduces respiratory rate and tissue carbon dioxide while increasing tidal and end-expiratory lung volumes: a randomised crossover trial. Thorax. 2016;71:759-61.

11. Réminiac F, Vecellio L, Heuzé-Vourc'h N, Petitcollin A, Respaud R, Cabrera $M$, et al. Aerosol therapy in adults receiving high flow nasal cannula oxygen therapy. J Aerosol Med Pulm Drug Deliv. 2016;29:134-41.

12. Bhashyam AR, Wolf MT, Marcinkowski AL, Saville A, Thomas K, Carcillo JA, et al. Aerosol delivery through nasal cannulas: an in vitro study. J Aerosol Med Pulm Drug Deliv. 2008;21:181-8.

13. Ari A, Harwood R, Sheard M, Dailey P, Fink JB. In vitro comparison of heliox and oxygen in aerosol delivery using pediatric high flow nasal cannula. Pediatr Pulmonol. 2011;46:795-801.

14. Sunbul FS, Fink JB, Harwood R, Sheard MM, Zimmerman RD, Ari A. Comparison of HFNC, bubble CPAP and SiPAP on aerosol delivery in neonates: an in vitro study. Pediatr Pulmonol. 2015;50:1099-106. 
15. Dailey PA, Harwood R, Walsh K, Fink JB, Thayer T, Gagnon G, Ari A. Aerosol delivery through adult high flow nasal cannula with heliox and oxygen. Respir Care. 2017;62:1186-92.

16. Réminiac F, Vecellio L, Loughlin RM, Le Pennec D, Cabrera M, HeuzéVourc'h $N$, et al. Nasal high flow nebulization in infants and toddlers: an in vitro and in vivo scintigraphic study. Pediatr Pulmonol. 2017;52:337-44.

17. Dugernier J, Hesse M, Jumetz T, Bialais E, Roeseler J, Depoortere V, et al. Aerosol delivery with two nebulizers through high-flow nasal cannula: a randomized cross-over single-photon emission computed tomography study. J Aerosol Med Pulm Drug Deliv. 2017;30:349-558.

18. Morgan SE, Mosakowski S, Solano P, Hall JB, Tung A. High-flow nasal cannula and aerosolized $\beta$ agonists for rescue therapy in children with bronchiolitis: a case series. Respir Care. 2015;60:e161-5.

19. Miller MR, Hankinson J, Brusasco V, Burgos F, Casaburi R, Coates A, et al. Standardisation of spirometry. Eur Respir J. 2005;26:319-38.

20. Radovanovic D, Pecchiari M, Pirracchio F, Zilianti C, D'Angerlo E, Santus P. Plethysmographic loops: a window on the lung pathophysiology of COPD patients. Front Physiol. 2018;9:484

21. Tantucci C. Expiratory flow limitation definition, mechanisms, methods, and significance. Pulm Med. 2013;2013:749860. https://doi. org/10.1155/2013/749860.
22. Nava S, Karakurt S, Rampulla C, Braschi A, Fanfulla F. Salbutamol delivery during non-invasive mechanical ventilation in patients with chronic obstructive pulmonary disease: a randomized, controlled study. Intensive Care Med. 2001;27:1627-35.

23. Stefan MS, Eckert P, Tiru B, Friderici J, Lindenauer PK, Steingrub JS. High flow nasal oxygen therapy utilization: 7-year experience at a community teaching hospital. Hosp Pract. 2018;46:73-6.

24. Bräunlich J, Wirtz H. Oral versus nasal high-flow bronchodilator inhalation in chronic obstructive pulmonary disease. J Aerosol Med Pulm Drug Deliv. 2018;31:248-54

25. Mauri T, Turrini C, Eronia N, Grasselli G, Volta CA, Bellani G, et al. Physiologic effects of high-flow nasal cannula in acute hypoxemic respiratory failure. Am J Respir Crit Care Med. 2017;195:1207-15.

26. Dhand R, Duarte AG, Jubran A, Jenne JW, Fink JB, Fahey PJ, et al. Dose response to bronchodilator delivered by metered dose inhaler in ventilator-supported patients. Am J Respir Crit Care Med. 1996;154:388-93.

\section{Submit your manuscript to a SpringerOpen ${ }^{\odot}$ journal and benefit from:}

- Convenient online submission

- Rigorous peer review

- Open access: articles freely available online

- High visibility within the field

- Retaining the copyright to your article

Submit your next manuscript at $\gg$ springeropen.com 